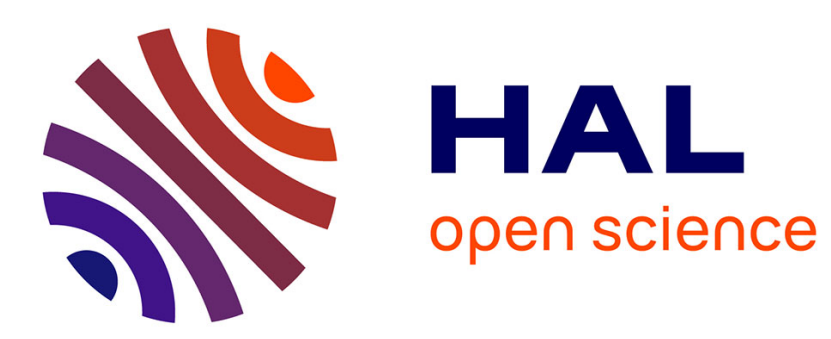

\title{
Isoprene Reactivity on Water Surfaces from ab initio QM/MM Molecular Dynamics Simulations
}

\author{
Marilia T.C. Martins-Costa, Manuel Ruiz-Lopez
}

\section{To cite this version:}

Marilia T.C. Martins-Costa, Manuel Ruiz-Lopez. Isoprene Reactivity on Water Surfaces from ab initio QM/MM Molecular Dynamics Simulations. ChemPhysChem, 2020, 21 (20), pp.2263-2271. 10.1002/cphc.202000652 . hal-03040026

\section{HAL Id: hal-03040026 \\ https://hal.science/hal-03040026}

Submitted on 4 Dec 2020

HAL is a multi-disciplinary open access archive for the deposit and dissemination of scientific research documents, whether they are published or not. The documents may come from teaching and research institutions in France or abroad, or from public or private research centers.
L'archive ouverte pluridisciplinaire HAL, est destinée au dépôt et à la diffusion de documents scientifiques de niveau recherche, publiés ou non, émanant des établissements d'enseignement et de recherche français ou étrangers, des laboratoires publics ou privés. 


\title{
Isoprene reactivity on water surfaces from ab initio QM/MM Molecular Dynamics simulations
}

\author{
Marilia T. C. Martins-Costa ${ }^{[a]}$ and Manuel F. Ruiz-López ${ }^{\text {[a] }}$
}

[a] Dr. M.T.C. Martins-Costa, Dr. M. F. Ruiz-Lopez

Laboratoire de Physique et Chimie Théoriques, UMR CNRS 7019

University of Lorraine, CNRS

BP 70239, 54506 Vandoeuvre-lès-Nancy, France

E-mail: marilia.martins-costa@univ-lorraine.fr, manuel.ruiz@univ-lorraine.fr

Supporting information for this article is given via a link at the end of the document.

\begin{abstract}
Isoprene is the most abundant volatile organic compound in the atmosphere after methane. While gas-phase processes have been widely studied, the chemistry of isoprene in aqueous environments is less well known. Nevertheless, some experiments have reported unexpected reactivity at the air-water interface. In this work, we have carried out combined quantum-classical molecular dynamics simulations of isoprene at the air-water interface, as well as ab initio and density functional theory calculations on isoprenewater complexes. We report the first calculation of the thermodynamics of adsorption of isoprene at the water surface, examine how hydration influences its electronic properties and reactivity indices, and estimate the $\mathrm{OH}$-initiated oxidation rate. Our study indicates that isoprene interacts with the water surface mainly through $\mathrm{H}-\pi$ bonding. This primary interaction mode produces strong fluctuations of the $\pi$ and $\pi^{*}$ bond stabilities, and therefore of isoprene's chemical potential, nucleophilicity and ionization potential, anticipating significant dynamical effects on its reactivity at the airwater interface. Using data from the literature and free energies reported in our work, we have estimated the rate of the $\mathrm{OH}$-initiated oxidation process at the air-water interface $\left(5.0 \times 10^{12}\right.$ molecule $\cdot \mathrm{cm}^{-}$ $\left.{ }^{3} \cdot \mathrm{s}^{-1}\right)$ to be about 7 orders of magnitude larger that the corresponding rate in gas-phase $\left(8.2 \times 10^{5}\right.$ molecule $\left.\cdot \mathrm{cm}^{-3} \cdot \mathrm{s}^{-1}\right)$. Atmospheric implications of this result are discussed.
\end{abstract}

\section{Introduction}

The chemistry of isoprene (2-methyl-1,3-butadiene, $\mathrm{C}_{5} \mathrm{H}_{8}$ ) has great environmental relevance. ${ }^{[1]}$ Isoprene, which is essentially emitted by plants, is the most abundant volatile organic compound (VOC) in the troposphere after methane, and represents about half of non-methane $\mathrm{VOC}$ gases. Its oxidation mechanisms ${ }^{[2,3]}$ strongly influence the $\mathrm{OH}, \mathrm{NO}_{x}$ and $\mathrm{O}_{3}$ atmospheric budgets, playing a role on aerosol formation as well. Its daytime half-life is about $1 \mathrm{~h}$. The oxidation process by $\mathrm{OH}$ is initiated by the addition of the radical to either $\mathrm{C}_{1}$ or $\mathrm{C}_{4}$, followed by a complex set of reactions with $\mathrm{O}_{2}$, leading to the formation of a variety of peroxy radical isomers $\left(\mathrm{RO}_{2}\right)$. The later can further react with either $\mathrm{NO}$, producing ozone and to a minor extent organic nitrates, or with $\mathrm{HO}_{2}$, resulting in hydroxy hydroperoxides, which are aerosol precursors. Some isomers can also undergo hydrogen-shift isomerization leading to hydroperoxy aldehydes and other compounds. Oxidation by $\mathrm{O}_{3}$ represents also a significant sink for isoprene, the corresponding ozonolysis process being a source of $\mathrm{OH}$ radicals, organic peroxy radicals, Criegee intermediates, and secondary organic aerosols.
Current knowledge of the chemistry of isoprene in the atmosphere still has major gaps, however, which limits the accuracy of current atmospheric models. ${ }^{[4]}$ One of such gaps is the role of water molecules on the chemistry of isoprene in different aqueous environments, which may change its reactivity. ${ }^{[5]}$ Since the solubility of isoprene in water is quite low (Henry's law constant about $1.3 \times 10^{-4} \mathrm{~mol} \cdot \mathrm{m}^{-3} \cdot \mathrm{Pa}^{-1}$ ), ${ }^{[6]}$ bulk phase chemistry is assumed to have minor importance (although it is not completely negligible ${ }^{[7]}$ ), but different experiments have emphasized the role of isoprene's chemistry at the surface of liquid water. Using electrospray-mass-spectrometry, Enami et $\mathrm{al}^{[8]}$ have studied the reactivity of isoprene at mildly acidic water surfaces and have concluded that isoprene can be protonated and undergo cationic oligomerisation. Kameel et $\mathrm{al}^{[9]}$ have reported data for the reaction of isoprene with $\mathrm{OH}$ in microdroplets generated by electrosprays showing that reactions lead to heavier products than in gas phase. The results suggest that at the surface of the droplets, after $\mathrm{OH}$ addition to isoprene, the reaction with another isoprene molecule is in competition with the reaction with $\mathrm{O}_{2}$. Qiu et $\mathrm{al}^{[10]}$ have studied the reactions of Criegee intermediates formed in the ozonolysis of monoterpenes at the surface of water evidencing the key role of water, which has also been proven in studies of gas-phase reactions involving such intermediates. ${ }^{[11-14]}$

Indeed, the so-called "on-water" catalytic effect ${ }^{[15]}$ presently represents one of the most fascinating issues in atmospheric chemistry. ${ }^{[16,17]}$ The rate of many reactions increases when they occur at aqueous interfaces, sometimes by several orders of magnitude with respect to the same process in gas phase or bulk water. However, there is not yet a complete understanding of this phenomenon. ${ }^{[17]}$ The confinement of the reactants or the formation of hydrogen-bonds with the dangling protons of interfacial waters have often been claimed to be the driving force for rate acceleration. But reactions of interest rarely occur on a neat water surface, and the influence of other factors such as the $\mathrm{pH}$, the dissociation of acids (see for instance Ref. ${ }^{[18-23]}$ ), or the distribution of cations and anions in the vicinity of the interfacial layer (see for instance Ref. ${ }^{[24-35]}$ ), need to be taken into account. Besides, the results of electrospray studies have raised some debate in the literature about the role of the highvoltages used in such experiments and possible role of gasphase charged species (see for instance the discussion about the protonation of isoprene $e^{[8]}$ in $\operatorname{Ref}^{[36-38]}$ ). For a more detailed discussion on all these issues, the reader is referred to a recent review about molecular reactions at aqueous interfaces, ${ }^{[17]}$ and to the references cited therein. 
Despite the potential importance of this chemistry, the interaction of isoprene with the water surface has not been studied yet, and only few theoretical studies have been devoted to isoprene-water complexes. Ito $^{[5]}$ reported IR data in noble gas matrices and theoretical calculations to study the structure isoprene-water 1:1 complexes, while Gallo et al ${ }^{[36]}$ carried out ab initio calculations to study the interaction of isoprene with protonated water clusters of different size to model processes in electrosprays. In order to get further insights into the water surface chemistry of isoprene, here we report theoretical calculations in different conditions that include 1:1 complexes, clusters of 21 waters and the planar surface of a water slab. We have carried out ab initio and density functional theory calculations for the clusters, and combined QM/MM molecular dynamics simulations for the extended system. We focus on the adsorption energetics and interaction modes on the neat water surface, as a necessary first step towards the understanding of the chemistry in more complex aqueous environments. We discuss the modifications of some reactivity indices of isoprene at the interface with respect to the gas-phase, and report an estimation of the $\mathrm{OH}$-initiated oxidation reaction rate in water microdroplets of atmospheric relevance.

\section{Results and Discussion}

\section{Structure of 1:1 complexes.}

The structure of isoprene:water 1:1 complexes has already been discussed in the literature at the B3LYP/6-31+G(2d,2p) level. ${ }^{[5]}$ The comparison of calculations with low-temperature infrared spectroscopy in noble gas matrices suggested that water preferentially forms $\mathrm{H}$-bonds with the $\mathrm{C}=\mathrm{C}$ double bonds. This is confirmed in our work by calculations at much higher levels. The geometries have been optimized here at the MP2/6$311+G(2 d f, 2 p)$, and for comparison, at the B3LYP/6$311+G(2 d f, 2 p)$ level too. Single-point energy calculations have then been carried out at the $\operatorname{CCSD}(T) / 6-311+G(2 d f, 2 p)$ level. The effect of increasing the basis set has been examined through calculations at the MP2/aug-cc-pVTZ level. The MP2 and B3LYP optimized structures are shown in Figure 1 and Figure S1, respectively. The Cartesian coordinates of all the optimized geometries are provided in the SI. The interactions energies are collected in Table 1.

One may note that the results at the $B 3 L Y P / 6-311+G(2 d f, 2 p)$ level are similar to those reported by Ito with a smaller basis set. ${ }^{[5]}$ Compared to the MP2 results, the B3LYP interaction energies are smaller, most likely due to the lack of dispersion in the DFT calculations. Attempts to refine the B3LYP geometries using different dispersion-corrected methods available in Gaussian $09^{[39]}$ were considered but calculations led to optimization convergence issues, so that we did not explore this option further. Single-point computations using either MP2 or $\operatorname{CCSD}(T)$ methods on B3LYP geometries, however, lead to results that do not differ greatly from those achieved with the MP2 geometries. Note also that MP2 provides similar energies to $\operatorname{CCSD}(T)$ calculations when the same geometries are used. All methods predict the two structures showing $\mathrm{H}-\mathrm{m}$ interactions (4-5) to be more stable than the structures (1-3) in which isoprene behaves as a proton donor. Their interaction energy is close to $-3.9 \mathrm{kcal} \cdot \mathrm{mol}^{-1}$ at the highest $\operatorname{CcSD}(\mathrm{T}) / 6$ -
$311+G(2 d f, 2 p) / / M P 2 / 6-311+G(2 d f, 2 p)$ level, this value being comparable to, though slightly larger than, the $\mathrm{H}-\mathrm{m}$ interaction in the benzene-water complex, $-3.29 \mathrm{kcal} \cdot \mathrm{mol}^{-1}$ in the $\operatorname{CCSD}(\mathrm{T}) / \mathrm{CBS}$ scheme of the S66 data set. ${ }^{[40]}$

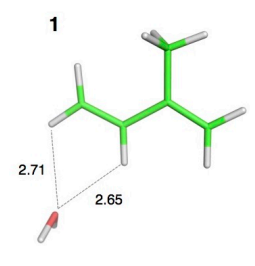

4

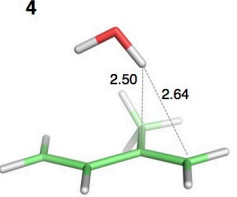

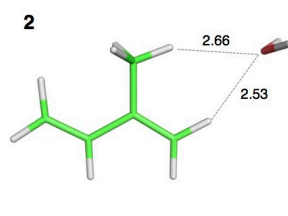

5

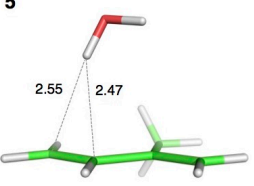

Figure 1. Optimized isoprene-water structures at the MP2/6-311+G(2df,2p) level. Distances in A. Structures 1-3 involve $\mathrm{H}$-bond interactions (isoprene $\mathrm{H}$ donor) while structures 4-5 involve $\mathrm{H}-\pi$ interactions (isoprene $\mathrm{H}$-acceptor).

Table 1. Calculated interaction energies of isoprene-water $1: 1$ complexes at different computational levels. The calculations assume the geometries optimized at the B3LYP (a) or MP2 (b) level with the $6-311+G(2 d f, 2 p)$ basis set. The interaction energies do not include zero-point contributions, which are indicated in parenthesis. Values in $\mathrm{kcal} \cdot \mathrm{mol}^{-1}$.

\begin{tabular}{|c|c|c|c|c|c|c|}
\hline & $\begin{array}{c}\text { B3LYP/ } \\
6-311+G(2 d f, 2 p)\end{array}$ & \multicolumn{2}{|c|}{$\begin{array}{c}M P 2 / \\
6-311+G(2 d f, 2 p)\end{array}$} & \multirow{2}{*}{ 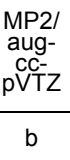 } & \multicolumn{2}{|c|}{$\begin{array}{c}\operatorname{CCSD}(T) / \\
6-311+G(2 d f, 2 p)\end{array}$} \\
\hline & a & a & b & & a & b \\
\hline 1 & $\begin{array}{l}-0.77 \\
(0.59)\end{array}$ & -1.45 & $\begin{array}{l}-1.76 \\
(0.68)\end{array}$ & -1.68 & -1.48 & -1.79 \\
\hline 2 & $\begin{array}{l}-0.95 \\
(0.66)\end{array}$ & -1.94 & $\begin{array}{l}-2.01 \\
(0.75)\end{array}$ & -1.96 & -1.96 & -2.02 \\
\hline 3 & $\begin{array}{l}-1.06 \\
(0.76)\end{array}$ & -2.15 & $\begin{array}{l}-2.23 \\
(0.83)\end{array}$ & -2.11 & -2.18 & -2.25 \\
\hline 4 & $\begin{array}{l}-2.10 \\
(1.08)\end{array}$ & -3.70 & $\begin{array}{l}-4.12 \\
(1.18)\end{array}$ & -4.20 & -3.48 & -3.85 \\
\hline 5 & $\begin{array}{l}-2.12 \\
(1.12)\end{array}$ & -3.73 & $\begin{array}{l}-4.16 \\
(1.26)\end{array}$ & -4.23 & -3.50 & -3.88 \\
\hline
\end{tabular}

\section{Structure of isoprene: $\left(\mathrm{H}_{2} \mathrm{O}\right)_{21}$ complexes.}

In this case, and due to the large size of the systems, the geometries have been optimized at the B3LYP/6-311+G(d) level and the interaction energies have been obtained by single-point energy calculations at the MP2 level with the same basis set. A similar theoretical approach has been used, together with the 21-water molecules cluster, to model the adsorption of other systems of atmospheric interest to the water surface. ${ }^{[41,42]}$ The optimized structures of different complexes are displayed in Figure 2 together with the interaction energies and relevant intermolecular distances. The Cartesian coordinates are reported in the SI. Two other structures were considered in which the interaction with the water cluster takes place through the $\mathrm{CH}_{2}$ groups of isoprene, but the optimization led to geometries close to that in structure 2 and to slightly smaller interaction energies. Therefore, for the sake of simplicity, they are not displayed in the Figure. Though one cannot exclude the existence of other minima, based on the results for the 1:1 
complexes, we assume that those represented in Figure 2 are the most relevant ones. The structures 1-5 are displayed by increasing interaction energy. In structures 1-3, isoprene behaves as a proton donor; structures 1 and 2 involve two $\mathrm{H}$ bonds and are a little less stable than structure $\mathbf{3}$, which involves three $\mathrm{H}$-bonds. Complex 4 displays two different types of bonds: one $\mathrm{H}$-bond with isoprene's methyl group (isoprene as proton donor) and one $\mathrm{H}-\mathrm{m}$ interaction with one of the $\mathrm{C}=\mathrm{C}$ double bonds (isoprene as proton acceptor). Finally, the most stable structure 5 displays two $\mathrm{H}-\pi$ interactions involving the two $\mathrm{C}=\mathrm{C}$ bonds in isoprene. The stability order found with the isoprene: $\left(\mathrm{H}_{2} \mathrm{O}\right)_{21}$ structures is consistent with the interaction energies obtained in the case of the 1:1 adducts, and confirms the large stabilizing contributions of isoprene-water $\mathrm{H}-\pi$ bonds.

\section{Adsorption at the surface of liquid water.}

We focus now on the thermodynamics of adsorption of isoprene at the surface of liquid water at finite temperature (298K). The free-energy of adsorption on water droplets is a fundamental quantity in atmospheric chemistry because, together with Henry's Law constant, it regulates the importance of aqueous phase chemistry. To this aim, QM/MM MD simulations have been carried out (see details in the computational section). They reveal that isoprene, despite its hydrophobic character, has nevertheless a significant affinity for the air-water interface. Two typical snapshots of the QM/MM MD simulations are displayed in Figure 3 and density profiles are shown in Figure 4. All along the simulations, isoprene remains at the surface of the water slab, and on average, its center of mass is only slightly above the formal interfacial plane. From the density profile, it is possible to estimate the free energy of adsorption. The corresponding curve, shown in Figure 4, displays a minimum at the interface that amounts $-4.6 \mathrm{kcal} \cdot \mathrm{mol}^{-1}$. This value is of the same order of magnitude, though a little larger than, the estimated free energy of adsorption of benzene $\left(3.8 \mathrm{kcal} \cdot \mathrm{mol}^{-}\right.$ $\left.{ }^{1}\right) .{ }^{[3]}$ By integrating along the free energy profile, it is also possible to estimate the equilibrium excess concentration at the air-water interface for a given air-concentration of isoprene. We obtain a ratio between the interface and gas phase concentration around 700 . Thus, for instance, for a reference gas-phase concentration in the atmosphere of $1 \mathrm{ppb}$, the concentration at the surface of a water droplet would be around $1.7 \times 10^{13}$ molecules $\cdot \mathrm{cm}^{-3}$. Qualitatively, this result is consistent with the findings of Gallo et $\mathrm{al}^{[36]}$ who showed that gaseous isoprene lowers the surface tension of water droplets by adsorbing to the surface, and it is very close to the estimation made by Huang et $\mathrm{al}^{\left[{ }^{[4]}\right.}$ using experimental data for other VOCs. One must note that this estimated concentration refers to the neat water surface. As for other VOCs, the actual concentration may differ from this value depending on the presence of other organics in the water layer, the ionic strength, the $\mathrm{pH}$, etc.

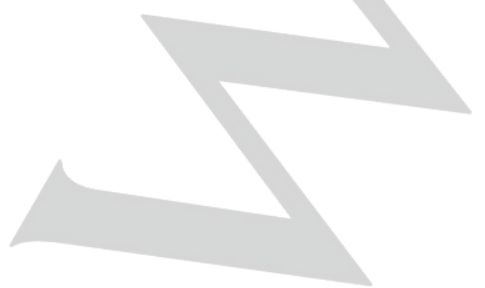

1

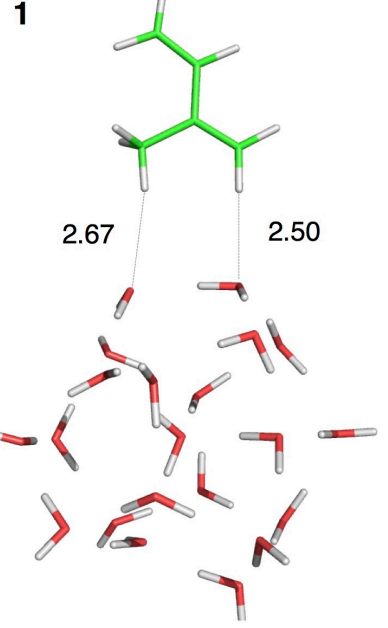

3

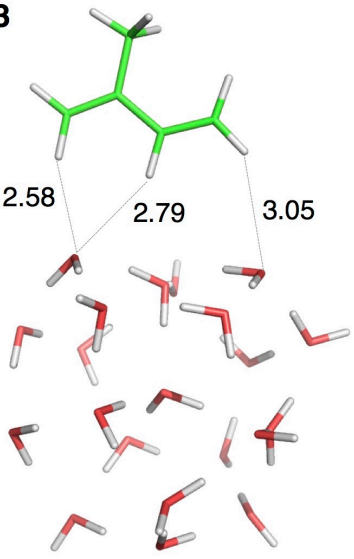

5

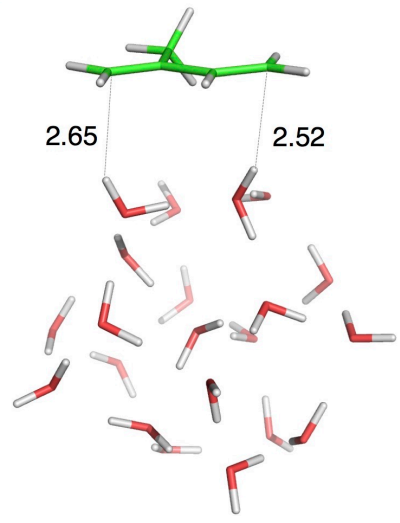

2<smiles>CC(C)C(C(C)C)C(C(C)C)C(C)C</smiles>

4

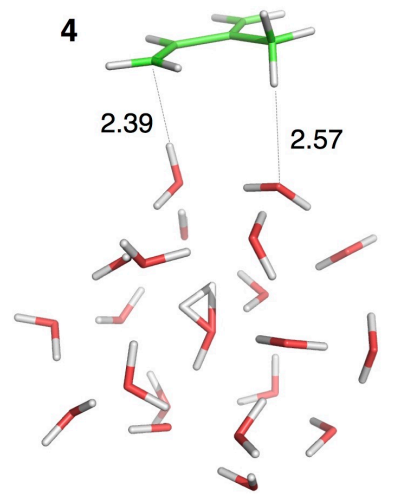

Figure 2. Structures of the isoprene: $\left(\mathrm{H}_{2} \mathrm{O}\right)_{21}$ complexes optimized at the B3LYP level and single-point interaction energies at MP2 level. In all cases, the $6-311+G(d)$ basis set has been employed. Distances in $\AA$, energies in $\mathrm{kcal} \cdot \mathrm{mol}^{-1}$. Only the shortest $\mathrm{H} \cdots \mathrm{C}$ distances in the $\mathrm{H}-\pi$ bond interactions are indicated. Structures 1-3 involve $\mathrm{H}$-bond interactions (isoprene $\mathrm{H}$-donor). Structure 4 involves one $\mathrm{H}-\pi$ interaction (left) and one $\mathrm{H}$-bond interaction (right). Structure $\mathbf{5}$ involves two $\mathrm{H}-\pi$ interactions (isoprene $\mathrm{H}$-acceptor). 

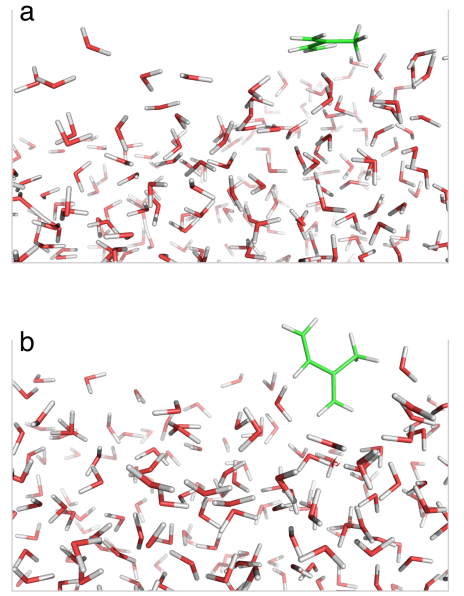

Figure 3. Snapshots from the QM/MM MD simulation of isoprene at the airwater interface: a) the isoprene molecular plane is parallel to the water surface and $\mathrm{H}-\pi$ interactions prevail, b) the $\mathrm{C}$-chain of isoprene is perpendicular to the water surface and $\mathrm{H}$-bond interactions prevail. In $\mathrm{b}$ ), the formation of a hydrophobic pocket at the interface is clearly seen.
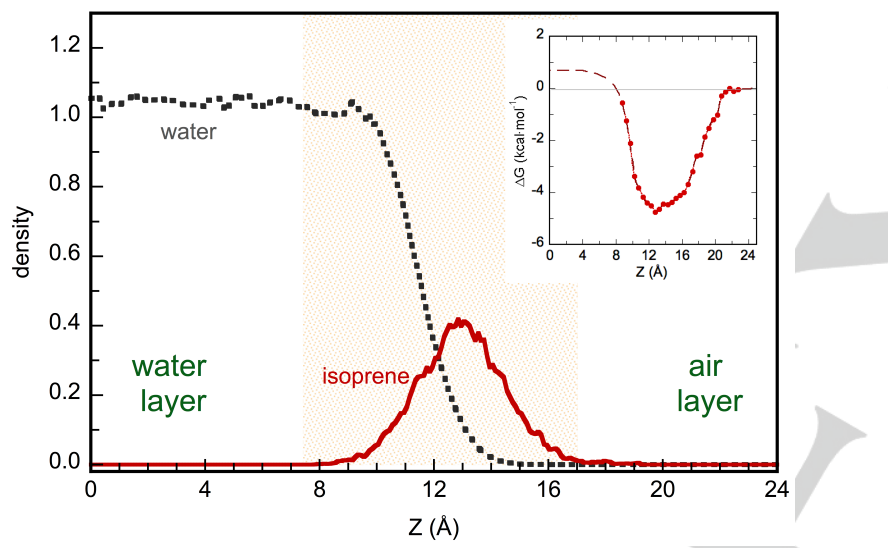

Figure 4. Molecular densities of water (black dots) and isoprene (plain red line) from the $300 \mathrm{ps} \mathrm{QM} / \mathrm{MM} \mathrm{MD}$ simulation at the air-water interface. Arbitrary units are used for isoprene and $\mathrm{g} \cdot \mathrm{cm}^{-3}$ units are used for water. The inset shows the free energy profile (red dots) deduced from the density profile (after horsetail sampling corrections). $Z=0$ corresponds to the centre of the simulation box. We assume that convergence in the air-layer has been reached at $Z=23 \AA$. We further assume the experimental value for the solvation free-energy in bulk water $\left(+0.68 \mathrm{kcal} \cdot \mathrm{mol}^{-1}\right)^{[45]}$. The red dashed line is an interpolation of the experimental and calculated points.

Let us now discuss in some detail how isoprene interacts with the water surface. The analysis of the orientational dynamics suggests that different interaction modes, such as those illustrated above with the 21 waters cluster, are at play. However, likewise in the 21 waters cluster, a preference for $\pi$ interactions is found. Figure 5 shows the distributions for the cosine of the angles $\theta, \varphi$ and $\chi$, which are defined, respectively, as the angles formed by the molecular in-plane vectors $\left(\mathbf{C}_{1} \mathbf{C}_{4}\right),\left(\mathbf{C}_{2} \mathbf{C}_{5}\right)$ and the normal vector $\mathbf{n}$ (see the Figure) with the $Z$-axis perpendicular to the surface. As shown, isoprene orientations with the $\left(\mathbf{C}_{1} \mathbf{C}_{4}\right)$ vector parallel to the interface are favored, while orientations of this vector perpendicular to the interface and C4 pointing towards the water layer are strongly disfavored. Similar trends are found for the $\left(\mathbf{C}_{2} \mathbf{C}_{5}\right)$ vector $\left(\mathrm{C}_{-}-\mathrm{CH}_{3}\right.$ bond). Moreover, if one looks at the distribution of the normal vector $\mathbf{n}$, one sees an orientational preference for configurations where the isoprene molecular plane lies parallel to the air-water interface ( $\mathbf{n}$ parallel to the $Z$ axis), as in snapshot (a) shown in Figure 3.

Further interesting information comes from the radial distribution functions (RDFs) shown in Figure 6. If one first considers the $\mathrm{H}$ (isoprene) $\cdots \mathrm{O}$ (water) RDFs, no particular interaction is found before or around $2.5 \AA$, indicating that the formation of hydrogen-bonds, with isoprene being the proton donor, is not favourable at the air-water interface. Looking now at the $\mathrm{C}$ (isoprene) $\cdots \mathrm{H}$ (water) RDFs, specific interactions between the carbon atoms of the butadiene motif and water are clearly seen. The RDFs for the $C_{1}$ and $C_{4}$ atoms shows well-differentiated peaks with maxima close to $2.3 \AA$. Similar features, but with less well-defined maxima, appear at around $2.6 \AA$ in the case of $\mathrm{C}_{2}$ and $\mathrm{C}_{3}$ atoms. The combination of the RDF results and the orientational analysis done before leads to the conclusion that isoprene interacts with the water surface mainly through two $\mathrm{H}-\pi$ interactions that favour the parallel arrangement of the isoprene molecular and water surface planes.
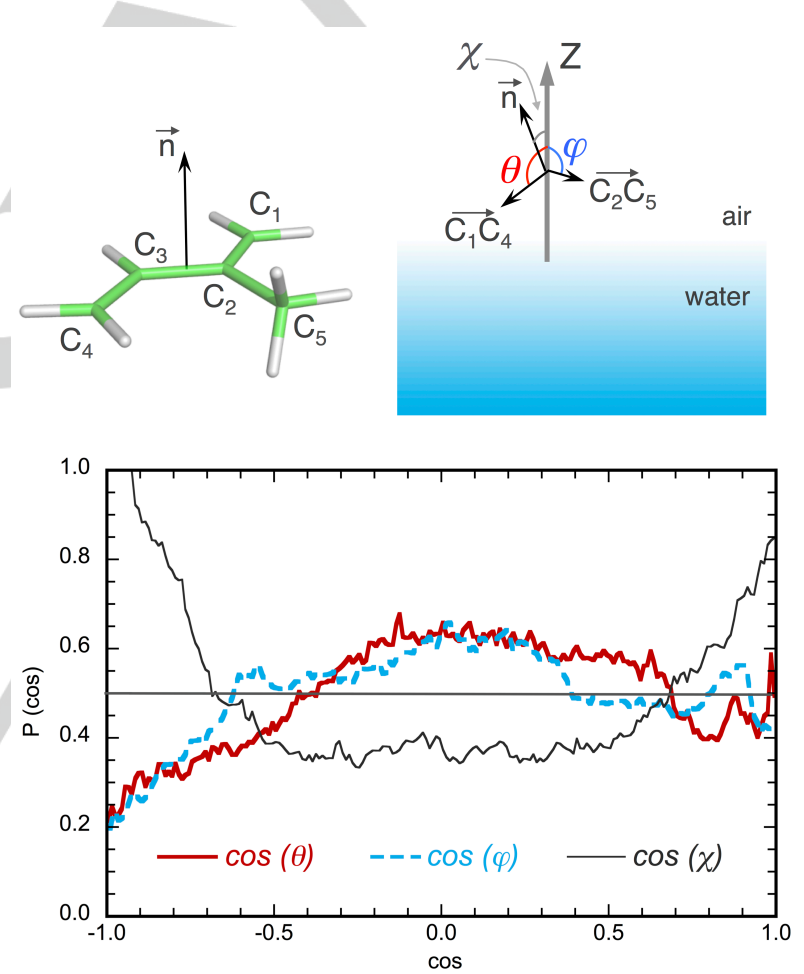

Figure 5. Orientational preference of isoprene at the air-water interface from QM/MM MD simulations. Distribution of $\cos (\theta), \cos (\varphi)$ and $\cos (\chi)$ for the angles formed by the vectors $\left(\mathbf{C}_{1} \mathbf{C}_{4}\right),\left(\mathbf{C}_{2} \mathbf{C}_{5}\right)$ and $\mathbf{n}=\left(\mathbf{C}_{1} \mathbf{C}_{4}\right) \times\left(\mathbf{C}_{2} \mathbf{C}_{5}\right)$ with the Z-axis. 


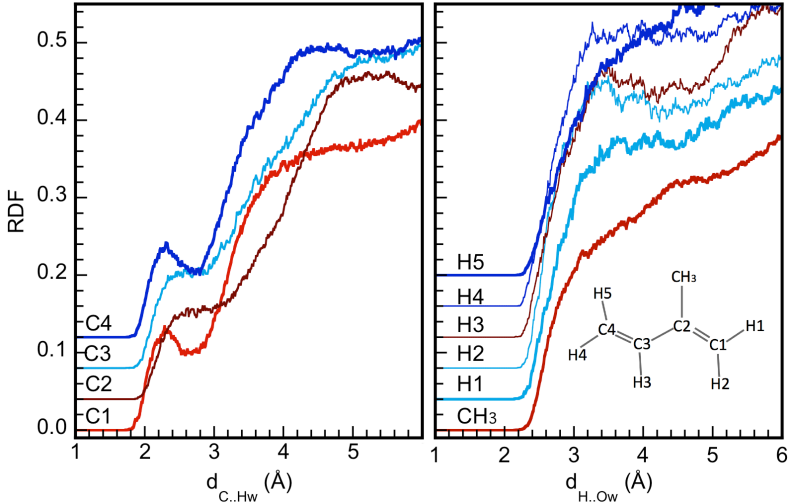

Figure 6. Radial distribution functions from the 300 ps QM/MM MD simulation. Left panel: $\mathrm{C}$ (isoprene) $\cdots \mathrm{H}$ (water). Right panel: $\mathrm{H}$ (isoprene) $\cdots \mathrm{O}$ (water). The $y$-axis tick values correspond to the $\mathrm{C} 1$ and $\mathrm{CH}_{3}$ curves. For clarity, the other curves have been shifted by steps of 0.04 . The curve $\mathrm{CH}_{3}$ corresponds to the average RDF of the three $\mathrm{H}$-atoms of the methyl group.

\section{Isoprene reactivity at the air-water interface.}

The large affinity displayed by isoprene for the air-water interface indicates that a significant part of its atmospheric chemistry is likely to occur in this medium. Some experimental studies have reported major differences for the interfacial chemistry of isoprene with respect to the corresponding gas phase chemistry, but a full understanding of such differences is still lacking. To further advance in this direction, in this work, we have considered two different aspects. First, we have examined the effect of hydration on isoprene reactivity indices at the airwater interface. Reactivity indices have been widely used in organic chemistry to interpret experimental data for reaction kinetics and selectivities. ${ }^{[46]}$ For instance, it has been shown that the proton affinity of organic compounds correlates well with a linear combination of the ionization energy, the softness, the electronegativity and electrophilicity indices, ${ }^{[47]}$ while the kinetics of $\mathrm{OH}$ addition to alkenes correlate well with the HOMO energy ${ }^{[48-50]}$ Besides, following Fukui's frontier molecular orbital theory ${ }^{[51]}$ and Woodward and Hoffmann rules, ${ }^{[52]}$ the Diels-Alder reactivity of isoprene, a common diene that can also act as a dieneophile, should be affected by the stability of the HOMO and LUMO. Hence, the analysis of reactivity indices will provide useful information on the interfacial reactivity of isoprene. Furthermore, we will consider the reaction of isoprene with $\mathrm{OH}$, which represents the most important sink for this VOC in the atmosphere. We will estimate the effect of adsorption on water on the reaction rates and will discuss the atmospheric impact of the obtained results.

Reactivity indices. According to the main isoprene-water surface interaction mode described above, one can expect significant modifications of isoprene's HOMO ( $\pi$ bond) and LUMO $(\pi *$ bond) orbital energies, and of other reactivity indices as well. We focus here on the ionization potential (approximated by minus the energy of the HOMO), the global softness (obtained as the reciprocal of the global hardness index $\eta$ ), the chemical potential $\mu$ and the nucleophilicy (obtained as the reciprocal of the electrophilicity index $\omega$ ), where approximately:

$\mu=\left(\epsilon_{\text {Номо }}+\epsilon_{\text {LUMO }}\right) / 2$

$\eta=\left(\epsilon_{\text {LUMO }}-\epsilon_{\text {Номо }}\right)$ $\omega=\mu^{2} / 2 \eta$

The derivation and validity of these equations, which are broadly used in the literature, have been reviewed before. ${ }^{[46,53]}$ In general, static values corresponding to energy minima are considered but the importance of incorporating dynamical effects on these indices has also been emphasized. ${ }^{[54-57]}$ Figure 7 displays the instantaneous value of these indices in the simulations in gas-phase and at the air-water interface. Table 2 provides the average values. A first striking result from the displayed data is the negligible effect of the surface adsorption process on the softness reactivity index: the average value is practically unchanged, and the time fluctuations at the interface are very similar to those in gas phase. In other words, the HOMO-LUMO gap in isoprene is not appreciably changed through interactions with water. This result suggests that the electronic absorption spectra of isoprene, which has relevance to understanding its photochemical behaviour, should not appreciably be shifted under adsorption on the water surface. The situation is quite different for other reactivity indices, which depend on the absolute HOMO and LUMO energy shifts, and not only on their relative value. Fluctuations at the picosecond timescale of the chemical and ionization potentials, and of the nucleophilicity index, are considerably greater at the interface compared to gas-phase. For instance, in the case of the nucleophilicity, peaks representing an increment of up to $100 \%$ are observed. These strong changes have to be attributed to the oscillations of the proton-acceptor and proton-donor interactions in the hydration shell surrounding isoprene. On average, however, these quantities do not change much with respect to gas-phase: $4 \%$ for the nucleophilicity, $1 \%$ for the chemical potential and roughly $0 \%$ for the ionization potential (i. e. the HOMO). Since kinetic constants are often correlated to reactivity indices, as mentioned above, the qualitative conclusion that can be derived from such results is that the rate of reactions involving isoprene at the air-water interface are probably not too different from the gas phase. In contrast, dynamic solvation effects are likely to be significant, especially when isoprene acts as a nucleophile, whereby the fluctuations of the solvent may be essential to drive the process. Indeed, isoprene dynamics and the lifetime of reaction intermediates are key factors in the complex chemistry of isoprene with $\mathrm{OH} .{ }^{[58]}$ Dynamic factors can alter, in particular, the relative reactivity of isoprene carbon atoms towards $\mathrm{OH}$, which is not the same, with $\mathrm{C}_{4}$ being a little preferred over $\mathrm{C}_{1}$, and with $\mathrm{C}_{2}$ and $\mathrm{C}_{3}$ playing a minor role in the gas-phase. ${ }^{[58]}$

Table 2. Average values of the reactivity indices of isoprene in gas-phase and at the air-water interface. Calculations at the B3LYP/6-311+G(d) level using snapshots from the simulations. Chemical and ionization potentials are given in $\mathrm{eV}$, and the other indices in $\mathrm{eV}^{-1}$. The averages were obtained over the MD trajectories of $25 \mathrm{ps}$ in gas-phase and $300 \mathrm{ps}$ at the air-water interface, showing in each case a suitable convergence.

\begin{tabular}{lllll}
\hline & $\begin{array}{l}\text { Chemical } \\
\text { potential }\end{array}$ & $\begin{array}{l}\text { lonization } \\
\text { potential }\end{array}$ & Softness & Nucleophilicity \\
\hline Gas-phase & -3.76 & 6.55 & 0.179 & 0.788 \\
\hline $\begin{array}{l}\text { Air-water } \\
\text { interface }\end{array}$ & -3.72 & 6.52 & 0.179 & 0.823 \\
\hline
\end{tabular}




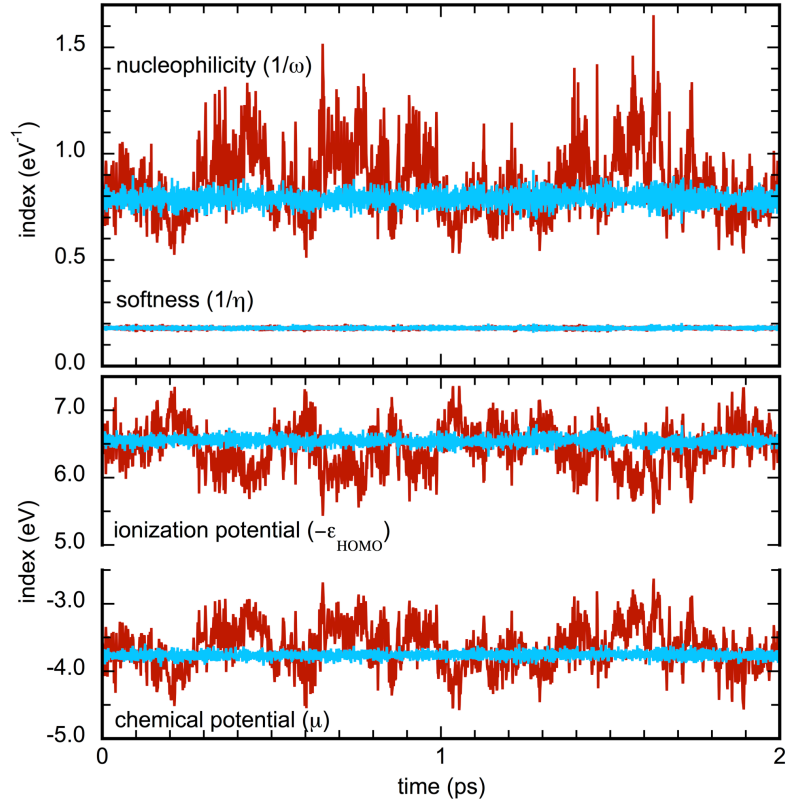

Figure 7. Detail along 2 ps of the fluctuations of some reactivity indices of isoprene in gas phase (light cyan) and at the air-water interface (red). Calculations at the B3LYP/6-311+G(d) level using snapshots from the simulations.

Oxidation rates at the interface and atmospheric implications. The main sink of isoprene in the troposphere is the reaction with $\mathrm{OH}$ radicals. Addition of $\mathrm{OH}$ to a double bond represents globally $85 \%$ of isoprene's reactive fate. Using data in the literature and the calculations reported here, it is possible to make an estimation of the $\mathrm{OH}$-initiated oxidation rate at the surface of cloud water droplets and of the contribution of this process to the overall oxidation of isoprene in the troposphere. The recommended IUPAC rate constant for the $\mathrm{OH}$-initiated oxidation of isoprene in gas phase is $2.86 \times 10^{-11} \mathrm{~cm}^{3} \cdot$ molecule ${ }^{1} \cdot \mathrm{s}^{-1}$ at $298 \mathrm{~K},{ }^{[2]}$ while the measured value in aqueous solution is $1.2 \times 10^{10} \mathrm{~L} \cdot \mathrm{mol}^{-1} \cdot \mathrm{s}^{-1}\left(2 \times 10^{-11} \mathrm{~cm}^{3} \cdot\right.$ molecule $\left.^{-1} \cdot \mathrm{s}^{-1}\right) \cdot{ }^{[4]}$ The rate constant at the interface is unknown but considering the moderate difference between gas phase and aqueous solution values, together with the small change of the average HOMO energy at the interface with respect to the gas phase, we will assume here $\mathrm{k}_{\text {inter }} \approx \mathrm{k}_{\text {gas }}$. The $\mathrm{OH}$ concentration in the gas phase is quite variable but $1.16 \times 10^{6}$ molecule $\cdot \mathrm{cm}^{-3}$ is a recommended annual average value. ${ }^{[59]}$ The equilibrium concentration at the interface can be calculated using free energy adsorption profiles from simulations, ${ }^{[60]}$ which leads to $1.0 \times 10^{10}$ molecule $\cdot \mathrm{cm}^{-3}$. This has to be considered as a lower limit, as the amount of $\mathrm{OH}$ radicals in water droplets might be much larger considering that the uptake from the gas phase is only one of the possible $\mathrm{OH}$ sources. ${ }^{[61]}$ Actually, the $\mathrm{OH}$ production rate in aqueous solution is up to 5 orders of magnitude larger than the production rate in the gas phase from ozone photolysis. ${ }^{[9]}$ The excess $\mathrm{OH}$ radicals in the droplet do not escape to the gas phase but are rapidly consumed by the organic compounds in the medium. As mentioned above, typical concentrations for isoprene in the troposphere amount $1 \mathrm{ppb}\left(2.46 \times 10^{10}\right.$ molecule $\left.\cdot \mathrm{cm}^{-3}\right)$ and our estimation at the interface is 700 times larger $\left(1.7 \times 10^{13}\right.$ molecules $\cdot \mathrm{cm}^{-3}$ ). The reaction rates $\mathrm{R}=\mathrm{k}[$ isoprene $][\mathrm{OH}]$ in these conditions in gas phase and at the air water interface are therefore estimated to be $R_{\text {gas }}=8.2 \times 10^{5}$ molecule $\cdot \mathrm{cm}^{-3} \cdot \mathrm{s}^{-1}$ and $R_{\text {inter }}=5.0 \times 10^{12}$ molecule $\cdot \mathrm{cm}^{-3} \cdot \mathrm{s}^{-1}$ (using the lower limit value for the concentration of $\mathrm{OH}$ radicals at the interface). In other words, we predict an interfacial reaction rate that is about 7 orders of magnitude larger than in gas phase. The overall contribution of clouds to the oxidation rate of isoprene in the troposphere will depend, however, on the water content of the clouds and the droplet size. In Figure 8, we have reported the relative interface/gas-phase absolute oxidation rates for values of liquid water content (LWC) between 0.2 and $1 \mathrm{~g} \cdot \mathrm{m}^{-3}$, which are characteristic in cumulus and cumulonimbus, as a function of droplet diameter $D$ (to obtain the effective interfacial layer volume, we have considered, as often done, ${ }^{[44,62]}$ spherical droplets with interfacial thickness of $1 \mathrm{~nm}$ ). Though the results have several uncertainties owing to the large variation of the concentrations and different thermodynamic conditions, they nevertheless show that interfacial processes may be quite significant, especially for high-water content clouds and small water-droplets. A previous estimation ${ }^{[44]}$ reported a contribution of about $16 \%$ for $L W C=1 \mathrm{~g} \cdot \mathrm{m}^{-3}$ and $D=0.2 \mu \mathrm{m}$. In the same conditions, we predict a larger value $(47 \%)$, which is basically due to the use of a more recent value for the gas-phase reaction rate. ${ }^{[63]}$

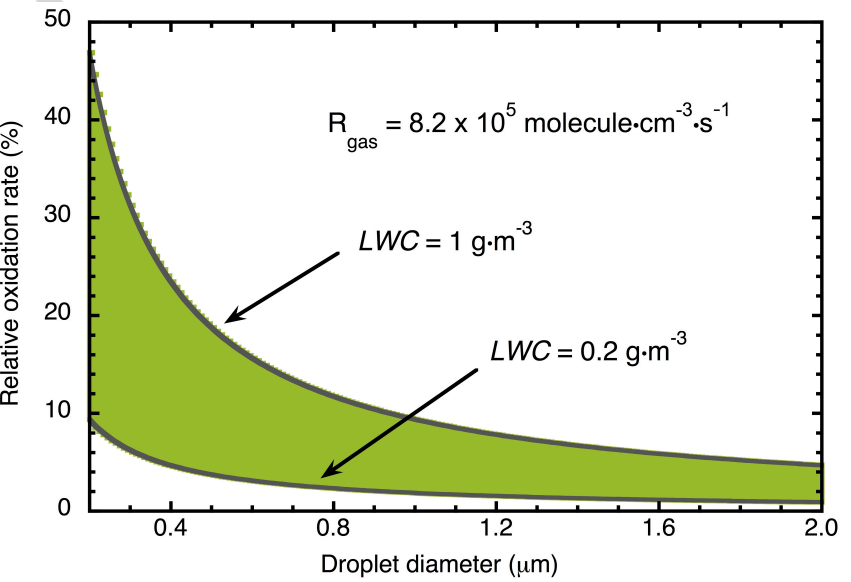

Figure 8. Estimated contribution of the oxidation of isoprene at the surface of water droplets in the troposphere with respect to gas phase (\%). The shaded area shows the relative absolute rates as a function of the droplet size in clouds with liquid water content $(L W C)$ between 0.2 and $1 \mathrm{~g} \cdot \mathrm{m}^{-3}$ of air. The reaction rate value in gas phase $\left(R_{\text {gas }}\right)$ is indicated.

\section{Conclusion}

The results of this work highlight how molecular interactions with a water surface can influence the gas-phase chemistry of hydrophobic compounds, which is a key topic to gain a better understanding of the atmospheric and environmental chemistry of volatile organic compounds.

According to our simulations, isoprene, whose solubility in water lies in the millimolar scale, nevertheless presents a significant affinity for the air-water interface, with an accumulation factor with respect to the gas-phase concentration of about 700 . This result, which is consistent with surface tension measurements and with previous estimations based on other VOC properties, is 
important to interpret laboratory experiments with microdroplets or bubbles, for instance, and field measurements in atmospheric and environmental waters.

In addition, our simulations reveal that $\mathrm{H}-\pi$ bonding is the dominant interaction mode with water molecules, resulting in a privileged parallel arrangement of the isoprene molecular plane with respect to the surface on average. As a consequence, the conjugated $\pi$-system is significantly polarized under the influence of the electric-field created by the surrounding water molecules. We have found that the fluctuations of this field produce strong modifications of the electronic properties at the picosecond time scale at room temperature. Eventually, the instantaneous values of the nucleophilicity and other reactivity indices are much larger compared to gas-phase values, suggesting that large dynamic solvation effects may affect the reactivity of isoprene at the interface.

We have also estimated the relative reaction rate for the $\mathrm{OH}$ initiated oxidation process of isoprene. According to our results, the reaction rate at the interface is about 7 orders of magnitude larger than in gas phase for typical atmospheric concentrations, so that interfacial chemistry can be significant for high water content clouds and/or for small water droplets.

\section{Computational Section}

Isoprene-water 1:1 complexes have been optimized at the B3LYP and MP2 levels of theory with the $6-311+G(2 d f, 2 p)$ basis set. Single-point energy calculations have then been carried out at the MP2 and CCSD(T) levels with the same basis set, as well as at the MP2/aug-cc-pVTZ level. For the calculation of zero-point energy contributions, the frequencies at the B3LYP and MP2 levels have been used. The initial structures were selected from those reported in a previous study at a lower level $B 3 L Y P / 6-31+G(2 d, 2 p) .{ }^{[5]}$ The interaction of isoprene with a cluster of 21 water molecules was studied at the MP2/6-311+G(d)//B3LYP/6-311+G(d) level. The choice of this cluster size was based on the results of previous studies that used it to model interactions with the water surface (see for instance $^{[41,42]}$ ). Different geometries were explored as initial structures, which were chosen on the basis of the results for the 1:1 complexes. Simulations at the air water interface were carried out using a $\mathrm{QM} / \mathrm{MM}$ approach $^{[64,65]}$ developed in our group ${ }^{[66-69]}$ that includes electrostatic embedding. Isoprene is described quantum mechanically (QM) and water molecules are described classically using the TIP3P force-field. ${ }^{[70]}$ The non-electrostatic solute-solvent $\mathrm{QM} / \mathrm{MM}$ interactions (repulsion and dispersion) are calculated using a Lennard-Jones potential. The LennardJones parameters for the QM system were taken from the OPLS forcefield. ${ }^{[71]}$ In order to maintain the computational cost within reasonable limits, isoprene was described at the HF/6-31G(d) level in the simulations Though calculations at the B3LYP with the same basis set are only slightly more costly (roughly by a factor of 4 for isoprene, using the software and computational environment described herein), the difference would represent however a significant additional computational effort considering the huge number of SCF and force calculations carried out in the present study (about $1.510^{7}$ ). We estimated the mean unsigned error in QM/MM interaction energies to be $0.3 \mathrm{kcal} \mathrm{mol}^{-1}$ (HF vs B3LYP with the $6-31 \mathrm{G}(\mathrm{d})$ basis set), which is an acceptable value representing about $5 \%$ of the average total interaction energy at B3LYP level. Simulations were carried out in the NVT ensemble ( $T=298 \mathrm{~K}$, NoséHoover thermostat ${ }^{[72,73]}$ ) for the solute and 499 water molecules within a box of size (in $\AA$ ) $24.685 \times 24.685 \times 130$. Periodic boundary conditions were used along the $X$ and $Y$ directions. The time step was $0.25 \mathrm{fs}$. After equilibration, the simulation was carried out for 300 ps. From this trajectory, 300000 snapshots were selected to calculate the electronic properties at the B3LYP/6-311+G(d) level. In addition, to improve the statistics, horsetail sampling ${ }^{[74,75]}$ was used by carrying out shorter simulations in parallel with randomized velocities along the previous simulation at constant time intervals (96 trajectories from 18 configurations chosen in the first half of the 300 ps simulation). A total simulation time of $3.5 \mathrm{~ns}$ was reached. The horsetail sampling was used to obtain the free energy profile in the interfacial layer. For comparison, a QM simulation (25 ps) of isolated isoprene was also carried out, and electronic properties were obtained at the same level (i. e. HF/6-31G(d) level for the MD simulations, followed by B3LYP/6-311+G(d) calculations for the properties). We use the Gaussian 09 program $^{[39]}$ for the QM calculations, Tinker $4.2^{[76]}$ for the MD simulations and the interface developed in our group. ${ }^{[55]}$

\section{Acknowledgements}

The authors acknowledge the French CINES for providing computational resources (Project LCT2550).

Keywords: Isoprene - air-water interface - QM/MM Molecular Dynamics simulations $\cdot \mathrm{OH}$ oxidation $\bullet$ on-water catalysis

[1] J. H. Seinfeld, S. N. Pandis, Atmospheric Chemistry and Physics: From Air Pollution to Climate Change, Wiley, New York, 2006

[2] P. O. Wennberg, K. H. Bates, J. D. Crounse, L. G. Dodson, R. C. McVay, L. A. Mertens, T. B. Nguyen, E. Praske, R. H. Schwantes, M. D. Smarte, Chem. Rev. 2018, 118, 3337-3390.

[3] K. H. Bates, D. J. Jacob, Atmos. Chem. Phys. 2019, 19, 9613-9640.

[4] P. Achakulwisut, L. J. Mickley, L. T. Murray, A. P. Tai, J. O. Kaplan, B. Alexander, Atmos. Chem. Phys. 2015, 15, 7977-7998.

[5] F. Ito, J. Mol. Spectrosc. 2017, 341, 27-34.

[6] R. Sander, Atmos. Chem. Phys. 2015, 15, 4399-4981.

[7] K. J. Rudziński, R. Szmigielski, I. Kuznietsova, P. Wach, D. Staszek, Atmos. Environ. 2016, 130, 163-171.

[8] S. Enami, H. Mishra, M. R. Hoffmann, A. J. Colussi, J. Phys. Chem. A. 2012, 116, 6027-6032.

[9] F. R. Kameel, M. Hoffmann, A. Colussi, J. Phys. Chem. A. 2013, 117, 5117-5123

[10] J. T. Qiu, S. Ishizuka, K. Tonokura, A. J. Colussi, S. Enami, J. Phys. Chem. A. 2018, 122, 7910-7917.

[11] P. Aplincourt, J. M. Anglada, J. Phys. Chem. A. 2003, 107, 5798-5811.

[12] P. Aplincourt, J. M. Anglada, J. Phys. Chem. A. 2003, 107, 5812-5820.

[13] P. Aplincourt, M. F. Ruiz-Lopez, J. Am. Chem. Soc. 2000, 122, 8990.

[14] Y. Sakamoto, R. Yajima, S. Inomata, J. Hirokawa, Phys. Chem. Chem. Phys. 2017, 19, 3165-3175.

[15] S. Narayan, J. Muldoon, M. G. Finn, V. V. Fokin, H. C. Kolb, K. B. Sharpless, Angew. Chem. Int. Ed. 2005, 44, 3275-3279.

[16] J. Zhong, M. Kumar, J. M. Anglada, M. T. C. Martins-Costa, M. F. RuizLopez, X. C. Zeng, J. S. Francisco, Annu. Rev. Phys. Chem. 2019, 70, 45-69.

[17] M. F. Ruiz-Lopez, J. S. Francisco, M. T. C. Martins-Costa, J. M. Anglada, Nat. Rev. Chem. 2020, in press, DOI:10.1038/s41570-41020-4020341572.

[18] E. S. Shamay, V. Buch, M. Parrinello, G. L. Richmond, J. Am. Chem. Soc. 2007, 129, 12910-12911.

[19] S. Z. Wang, R. Bianco, J. T. Hynes, J. Phys. Chem. A. 2009, 113, 12951307.

[20] M. D. Baer, D. J. Tobias, C. J. Mundy, J. Phys. Chem. C. 2014, 118, 29412-29420.

[21] H. Mishra, S. Enami, R. J. Nielsen, M. R. Hoffmann, W. A. Goddard, A. J. Colussi, Proc. Natl. Acad. Sci. USA. 2012, 109, 10228-10232.

[22] H. Mishra, S. Enami, R. J. Nielsen, L. A. Stewart, M. R. Hoffmann, W. A. Goddard, A. J. Colussi, Proc. Natl. Acad. Sci. USA. 2012, 109, 1867918683.

[23] G. Murdachaew, G. M. Nathanson, R. B. Gerber, L. Halonen, Phys. Chem. Chem. Phys. 2016, 18, 29756-29770. 
[24] P. B. Petersen, R. J. Saykally, Annu. Rev. Phys. Chem. 2006, 57, 333 364

[25] D. Ben-Amotz, J. Phys. Condens. Matt. 2016, 28, 414013.

[26] T. T. Duignan, D. F. Parsons, B. W. Ninham, J. Phys. Chem. B. 2014, 118, 8700-8710.

[27] Y. Tong, I. Y. Zhang, R. K. Campen, Nat. Comm. 2018, 9, 1313.

[28] L. Sun, X. Li, Y. Q. Tu, H. Agren, Phys. Chem. Chem. Phys. 2015, 17, 4311-4318.

[29] Y. Levin, A. P. dos Santos, J. Phys. Condens. Matt. 2014, 26, 203101.

[30] T. L. Beck, Chem. Phys. Lett. 2013, 561, 1-13.

[31] D. J. Tobias, A. C. Stern, M. D. Baer, Y. Levin, C. J. Mundy, Annu. Rev. Phys. Chem. 2013, 64, 339-359.

[32] S. M. Kathmann, I. F. W. Kuo, C. J. Mundy, J. Am. Chem. Soc. 2008, 130 , 16556-16561.

[33] D. E. Otten, P. R. Shaffer, P. L. Geissler, R. J. Saykally, Proc. Natl. Acad. Sci. USA. 2012, 109, 701-705.

[34] P. Jungwirth, D. J. Tobias, Chem. Rev. 2006, 106, 1259-1281.

[35] C. Caleman, J. S. Hub, P. J. van Maaren, D. van der Spoel, Proc. Natl. Acad. Sci. USA. 2011, 108, 6838-6842.

[36] A. Gallo, A. S. F. Farinha, M. Dinis, A.-H. Emwas, A. Santana, R. J. Nielsen, W. A. Goddard, H. Mishra, Chem. Sci. 2019, 10, 2566-2577.

[37] A. J. Colussi, S. Enami, Chem. Sci. 2019, 10, 8253-8255.

[38] A. Gallo, A. S. F. Farinha, A. H. Emwas, A. Santana, R. J. Nielsen, W. A. Goddard, H. Mishra, Chem. Sci. 2019, 10, 8256-8261.

[39] M. J. Frisch, G. W. Trucks, H. B. Schlegel, G. E. Scuseria, M. A. Robb, J. R. Cheeseman, G. Scalmani, V. Barone, B. Mennucci, G. A. Petersson, H. Nakatsuji, M. Caricato, X. Li, H. P. Hratchian, A. F. Izmaylov, J. Bloino, G. Zheng, J. L. Sonnenberg, M. Hada, M. Ehara, K. Toyota, R. Fukuda, J. Hasegawa, M. Ishida, T. Nakajima, Y. Honda, O. Kitao, H. Nakai, T. Vreven, J. A. Montgomery Jr., J. E. Peralta, F. Ogliaro, M. J. Bearpark, J. Heyd, E. N. Brothers, K. N. Kudin, V. N. Staroverov, R. Kobayashi, J. Normand, K. Raghavachari, A. P. Rendell, J. C. Burant, S. S. Iyengar, J. Tomasi, M. Cossi, N. Rega, N. J. Millam, M. Klene, J. E. Knox, J. B. Cross, V. Bakken, C. Adamo, J. Jaramillo, R. Gomperts, R. E. Stratmann, O. Yazyev, A. J. Austin, R. Cammi, C. Pomelli, J. W. Ochterski, R. L. Martin, K. Morokuma, V. G. Zakrzewski, G. A. Voth, P. Salvador, J. J. Dannenberg, S. Dapprich, A. D. Daniels, Ö. Farkas, J. B. Foresman, J. V. Ortiz, J. Cioslowski, D. J. Fox, Gaussian 09, Gaussian, Inc., Wallingford, CT, USA, 2009.

[40] J. Řezáč, K. E. Riley, P. Hobza, J. Chem. Theor. Comput. 2011, 7, 34663470.

[41] M. Torrent-Sucarrat, M. F. Ruiz-Lopez, M. Martins-Costa, J. S. Francisco, J. M. Anglada, Chem. Eur. J. 2011, 17, 5076-5085.

[42] M. F. Ruiz-Lopez, M. T. Martins-Costa, J. M. Anglada, J. S. Francisco, J. Am. Chem. Soc. 2019, 141, 16564-16568.

[43] T. P. Liyana-Arachchi, K. T. Valsaraj, F. R. Hung, J. Phys. Chem. A. 2012, 116, 8539-8546

[44] D. Huang, X. Zhang, Z. Chen, Y. Zhao, X. Shen, Atmos. Chem. Phys. 2011, 11, 7399-7415.

[45] M. H. Abraham, J. Andonian-Haftvan, G. S. Whiting, A. Leo, R. S. Taft, J. Chem. Soc. Perkin Trans. 2. 1994, 1777-1791.

[46] P. Geerlings, F. De Proft, W. Langenaeker, Chem. Rev. 2003, 103, 1793 1874.

[47] S. K. Rajak, N. Islam, D. C. Ghosh, in Carbon Bonding and Structures. Advanced in Physics and Chemistry (Ed.: M. V. Putz), Springer, Heidelberg London New York, 2011, pp. 321-335.

[48] M. D. King, C. E. Canosa-Mas, R. P. Wayne, Phys. Chem. Chem. Phys. 1999, 1, 2239-2246.

[49] R. Atkinson, J. Phys. Chem. Ref. Data. 1997, 26, 215-290.

[50] M. D. King, C. E. Canosa-Mas, R. P. Wayne, Phys. Chem. Chem. Phys. 1999, 1, 2231-2238.

[51] K. Fukui, Science. 1982, 218, 747-754.

[52] R. B. Woodward, R. Hoffmann, Angew. Chem. Int. Ed. Engl. 1969, 8, 781853.

[53] S. B. Liu, Acta Phys.-Chim. Sin. 2009, 25, 590-600.

[54] S. B. Liu, J. Chem. Sci. 2005, 117, 477-483.

[55] M. T. C. Martins-Costa, M. F. Ruiz-López, Chem. Phys. 2007, 332, 341 347.
[56] M. T. C. Martins-Costa, F. F. Garcia-Prieto, M. F. Ruiz-Lopez, Org. \& Biomol. Chem. 2015, 13, 1673-1679.

[57] G. Hoffmann, V. Tognetti, L. Joubert, Chem. Phys. Lett. 2019, 724, 24-28.

[58] A. P. Teng, J. D. Crounse, P. O. Wennberg, J. Am. Chem. Soc. 2017, 139, 5367-5377.

[59] P. Warneck, J. Williams, The Atmospheric Chemist's Companion. Numerical Data for Use in the Atmospheric Sciences, Springer Netherlands, 2012.

[60] R. Vácha, P. Slavíček, M. Mucha, B. J. Finlayson-Pitts, P. Jungwirth, J. Phys. Chem. 2003, 108, 11573-11579.

[61] S. E. Paulson, P. J. Gallimore, X. B. M. Kuang, J. R. Chen, M. Kalberer, D. H. Gonzalez, Sci. Adv. 2019, 5, Art. Nr. eaav7689.

[62] M. T. C. Martins-Costa, J. M. Anglada, J. S. Francisco, M. F. Ruiz-Lopez, J. Am. Chem. Soc. 2012, 134, 11821-11827.

[63] R. Atkinson, D. L. Baulch, R. A. Cox, J. N. Crowley, R. F. Hampson, R. G. Hynes, M. E. Jenkin, M. J. Rossi, J. Troe, Atmos. Chem. Phys. 2006, 6, 3625-4055.

[64] M. J. Field, P. A. Bash, M. Karplus, J. Comput. Chem. 1990, 11, 700-733.

[65] A. Warshel, M. Levitt, J. Mol. Biol. 1976, 103, 227-249.

[66] I. Tuñón, M. T. C. Martins-Costa, C. Millot, M. F. Ruiz-Lopez, Chem. Phys. Lett. 1995, 241, 450-456.

[67] I. Tuñón, M. T. C. Martins-Costa, C. Millot, M. F. Ruiz-López, J. Mol. Mod. 1995, 1, 196-201.

[68] I. Tuñón, M. T. C. Martins-Costa, C. Millot, M. F. Ruiz-López, J. Chem. Phys. 1997, 106, 3633-3642.

[69] I. Tuñón, M. T. C. Martins-Costa, C. Millot, M. F. Ruiz-López, J. L. Rivail, J. Comp. Chem. 1996, 17, 19-29

[70] W. L. Jorgensen, J. Chandrashekar, J. D. Madura, W. R. Impey, M. L. Klein, J. Chem. Phys. 1983, 79, 926-935.

[71] W. L. Jorgensen, J. Tirado-Rives, J. Am. Chem. Soc. 1988, 110, 16571666.

[72] W. G. Hoover, Phys. Rev. A 1985, 31, 1695-1697.

[73] S. Nosé, J. Chem. Phys. 1984, 81, 511-519.

[74] M. T. C. Martins - Costa, M. F. Ruiz - López, J. Comput. Chem. 2017, 38, 659-668.

[75] M. T. C. Martins-Costa, M. F. Ruiz-López, Theoret. Chem. Acc. 2017, 136, 50.

[76] J. W. Ponder, TINKER: Software Tools for Molecular Design Washington University School of Medicine: Saint Louis, MO., 2004 


\section{Entry for the Table of Contents}

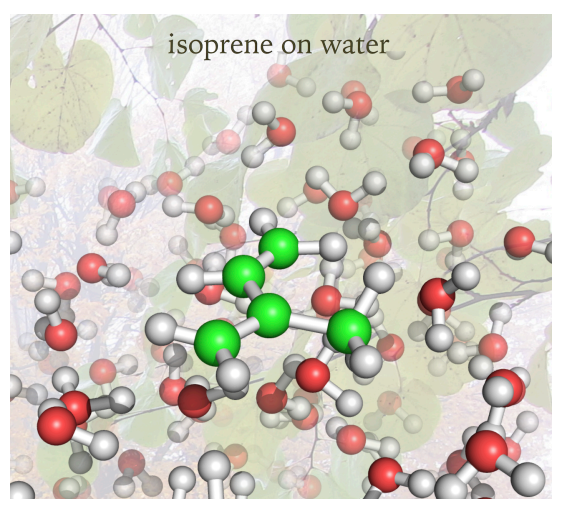

First-principles QM/MM molecular dynamics simulations show that isoprene has a significant affinity for the air-water interface. The adsorption process is driven by $\mathrm{H}-\pi$ interactions, which significantly modify the electronic properties and the reactivity of this volatile organic compound. The potential implications of the results in atmospheric chemistry are discussed.

Institute and/or researcher Twitter usernames: @Univ_Lorraine @CNRS_Centre_Est 